\title{
Antiviral and lung protective activity of a novel respiratory syncytial virus fusion inhibitor in a mouse model
}

\author{
W. Olszewska*, G. Ispas*, C. Schnoeller*, D. Sawant*, T. Van de Casteele ${ }^{\#,}$ \\ D. Nauwelaers", B. Van Kerckhove", D. Roymans" ${ }^{\#}$ M. De Meulder ${ }^{+}$, M.C. Rouan\#, \\ P. Van Remoortere", J.F. Bonfanti" , F. Van Velsen" ${ }^{\#}$ A. Koul", M. Vanstockem", \\ K. Andries ${ }^{\#}$, P. Sowinski*, B. Wang*, P. Openshaw* and R. Verloes ${ }^{\#}$
}

ABSTRACT: Respiratory syncytial virus (RSV) causes bronchiolitis in young children and common colds in adults. There is no licensed vaccine, and prophylactic treatment with palivizumab is very expensive and limited to high-risk infants. Ribavirin is used as an antiviral treatment in infants and immunosuppressed patients, and its use is limited due to side-effects, toxicity to the recipient and staff, and evidence of marginal clinical efficacy. Therefore, we studied the in vivo kinetics, and the antiviral and protective properties of a novel candidate for RSV disease treatment.

The drug is a small molecule (TMC353121) discovered by screening for fusion inhibitory properties against RSV in a cellular infection model. The pharmacokinetics of TMC353121 was studied in BALB/c mice and antiviral effects determined by testing viral loads in lung tissue by quantitative RT-PCR and plaque assay after intranasal RSV infection.

At doses of $0.25-10 \mathrm{mg} \cdot \mathrm{kg}^{-1}$, TMC353121 significantly reduced viral load, bronchoalveolar lavage cell accumulation and the severity of lung histopathological change after infection. Treatment remained effective if started within $48 \mathrm{~h}$ of infection, but was ineffective thereafter.

Therefore, TMC353121 is a novel potent antiviral drug, in vivo reducing RSV replication and inhibiting consequential lung inflammation, with a great potential for further clinical development.

KEYWORDS: Antiviral therapy, fusion inhibitor, respiratory syncytial virus

$\mathbf{R}$ espiratory syncytial virus (RSV) is a causative agent of common colds in adults, and is responsible for severe bronchiolitis and viral pneumonia in infants and young children [1, 2]. Viral bronchiolitis is one of the leading causes of hospitalisation of infants aged under $1 \mathrm{yr}$ [3], and is associated with the development of recurrent wheezing or asthma in later childhood [4]. Children born prematurely, as well as those with chronic lung disease or congenital heart disease, are at highest risk for severe disease and hospitalisation due to RSV. In elderly persons, RSV infection is associated with lower respiratory tract symptoms, leading to complications when concomitant conditions are present [5]. The disease burden of RSV infection in the elderly and in adults at risk is similar to that of nonpandemic influenza in a population with high prevalence of vaccination for influenza [6].
Currently, three drugs have been approved for use against RSV infection but the treatment of RSV disease remains mainly symptomatic. Ribavirin is used for serious RSV infections in infants with severe bronchiolitis and in immunocompromised patients. However, its use is limited due to highly variable efficacy and toxicity risks [7]. RespiGam ${ }_{\mathbb{R}}$ (no longer available) and Synagis $₫$ (palivizumab), polyclonal and monoclonal antibodies respectively, were designed for prophylaxis, but are very expensive and hence use is limited in many settings by financial considerations [8, 9]. Motavizumab (Numax ${ }^{\circledR}$ ), an improved monoclonal antibody under consideration for market approval, is expected to have therapeutic indications similar to palivizumab [10].

Attempts to develop a safe and effective RSV vaccine have been unsuccessful to this date.
AFFILIATIONS

${ }^{*}$ Centre for Respiratory Infection, Imperial College London, London, UK. "TTibotec BVBA, -Virco BVBA, Mechelen, and +Johnson and Johnson Pharmaceutical Research and Development, Janssen Pharmaceutica N.V., Beerse, Belgium.

CORRESPONDENCE W. Olszewska Centre for Respiratory Infection Imperial College London St Mary's Campus Norfolk Place Paddington W2 $1 \mathrm{PG}$ London UK E-mail:w.olszewska@ medrescom.co.uk

Received: Jan 122010 Accepted after revision: Nov 112010 First published online: Dec 092010 
Formalin-inactivated vaccines did not protect against natural infection and even led to enhanced disease [11]. Liveattenuated vaccines have been tried with limited success. Clearly, there is a need for an efficacious, nontoxic and easy to administer drug against RSV infection, with both prophylactic and therapeutic potency.

One potential therapeutic target for an antiviral drug is the RSV entry process into lung epithelial cells. The F (fusion) protein is crucial in this process and thus plays a critical role in establishing an infection. Several small molecule inhibitors of the fusion process have been identified [12-17], but most were discontinued for scientific or strategic reasons [18].

The RSV fusion inhibitor TMC353121 has been developed from the precursor molecule JNJ-2408068 [17] using a molecular modelling approach. It maintains high activity (pEC50 9.9) and low cytotoxicity, while presenting a shorter retention time in the lung (lung $t_{1 / 2} 25 \mathrm{~h}$ ) [19]. The mechanism of action of TMC353121 has been confirmed in time-ofaddition and in vitro resistant mutant selection studies. TMC353121 was found to inhibit RSV by preventing both virus cell fusion and syncytia formation by causing a local disturbance of the natural six-helix bundle conformation of RSV-F protein [20].

In this article, we show that TMC353121, administered prophylactically or therapeutically, has potent antiviral properties in vivo in a BALB/c mice model and protects against lung infection and virus-induced inflammation.

\section{MATERIALS AND METHODS}

\section{Animals and drug administration}

Inbred 8- to 12-week-old female BALB/c mice were purchased from Harlan Olac Ltd (Bicester, UK), and maintained in pathogen-free conditions. The human RSV A2 strain was plaque-purified and selected in HEp-2 cells. The protocols were carried out under licence from the UK Home Office.

TMC353121 [19, 21] was administered intravenously in saline at doses of $0.25-10 \mathrm{mg} \cdot \mathrm{kg}^{-1}$, and at various times in relation to the RSV infection (fig. 1a). Mice were infected with $2 \times 10^{6}$ plaqueforming unit (PFU) of plaque-purified human strain RSV A2 (100 $\mu \mathrm{L}$ intranasally). Individual body weight was used to monitor animal health and response to infection, and was recorded daily.

\section{RSV detection in the lung}

Real-time RT-PCR

RNA was extracted from homogenised lung tissue using the RNeasy kit (Qiagen, Crawley, UK) following the manufacturer's instructions. Total RNA concentration was determined by a spectrophotometer at $260 \mathrm{~nm}$, and cDNA was generated using random primers (Promega, Southampton, UK) and the Omniscript RT-kit (Qiagen).

Viral load measurements were conducted using RT-PCR, specific for the RSV L-gene, using TaqMan chemistry (Applied Biosystems, Life Technologies Ltd, Paisley, UK) and the ABI Prism 7500 Fast-Real-Time PCR System (Life Technologies Ltd). The PCR assay consisted of $50^{\circ} \mathrm{C}$ for $5 \mathrm{~min}$ and $95^{\circ} \mathrm{C}$ for $10 \mathrm{~min}$, prior to 40 cycles of $15 \mathrm{~s}$ at $96^{\circ} \mathrm{C}$ and $1 \mathrm{~min}$ at $60^{\circ} \mathrm{C}$.

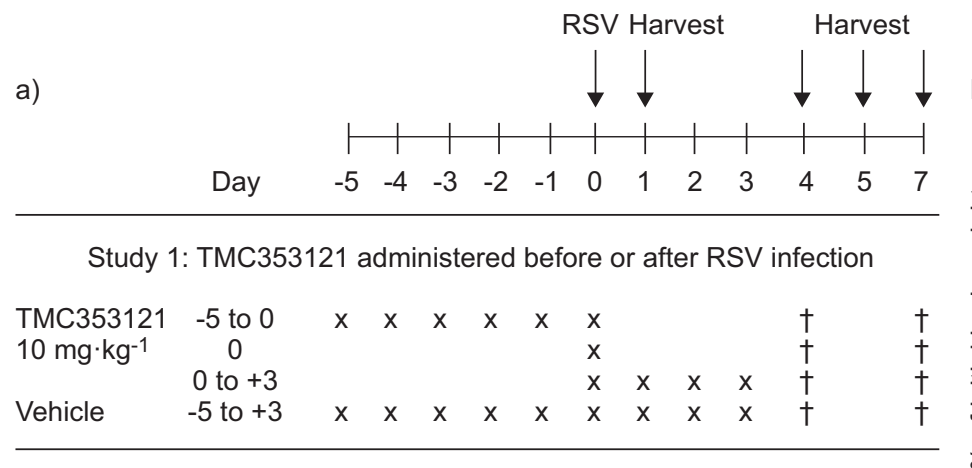

Study 2: TMC353121 administered after RSV infection

\begin{tabular}{|c|c|c|c|c|c|}
\hline TMC353121 & 0 to +3 & $\mathrm{x}$ & $\mathrm{x}$ & $x$ & $x$ \\
\hline $10 \mathrm{mg} \cdot \mathrm{kg}^{-1}$ & +1 to +3 & & $\mathrm{x}$ & $\mathrm{x}$ & $\mathrm{x}$ \\
\hline & $\begin{array}{c}+2 \text { to }+3 \\
+3\end{array}$ & & & $x$ & $\begin{array}{l}x \\
x\end{array}$ \\
\hline Vehicle & 0 to +4 & $x$ & $x$ & $x$ & $x$ \\
\hline
\end{tabular}

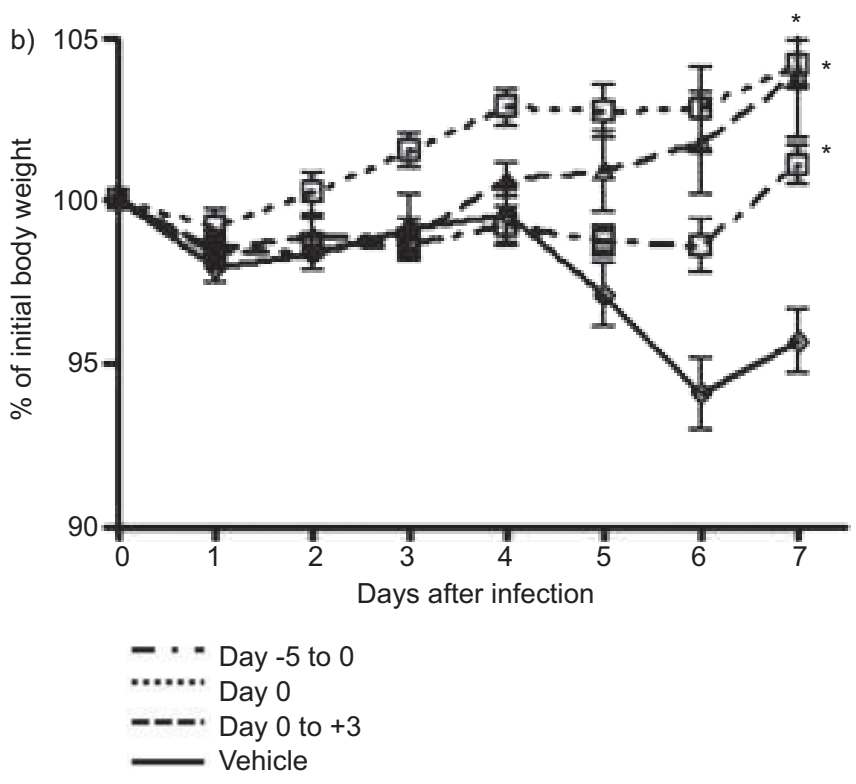

$\begin{array}{lllll}\text { TMC353121 } & & & & \\ 0.25-10 & 0 & & \dagger & \dagger \\ \mathrm{mg} \cdot \mathrm{kg}^{-1} & & \mathrm{x} & \dagger & \dagger \\ \text { Vehicle } & 0 & & \dagger\end{array}$

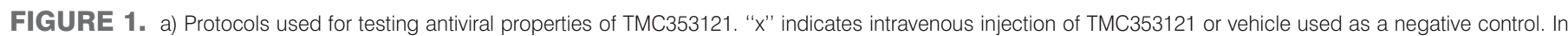

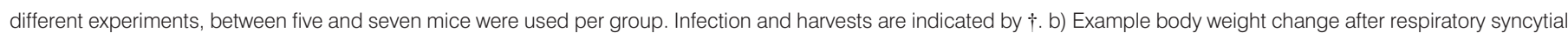

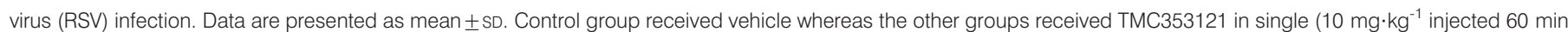

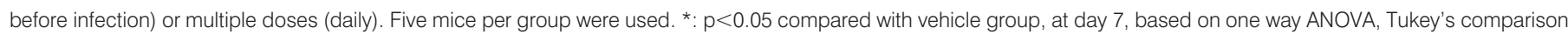
test. No significant differences were observed between treated groups at day 7 . 
QuantiTect Probe PCR master mix (Qiagen), $900 \mathrm{nM}$ forward primer (GAA CTC AGT GTA GGT AGA ATG TTT GCA), $300 \mathrm{nM}$ reverse primer (TTC AGC TAT CAT TTT CTC TGC CAA T) and $100 \mathrm{nM}$ probe (6FAM-TTTGAACCTGTCTGAAC ATTCCCGGTT-TAMRA) were used. The limit of detection was 10 copies of RSV-L gene. Quantification was performed from standard curves of a pcDNA3 plasmid carrying a fragment of the RSV L-gene. Results are expressed as RSV-L gene copy numbers and transformed in $\log _{10}$ values. The antiviral effect of TMC353121 is expressed as median log reduction versus untreated control $\left(\Delta \log _{10}\right)$.

\section{Plaque assay}

Lungs harvested 4 days after virus challenge were homogenised, centrifuged for $4 \mathrm{~min}$ at $700 \times g$, and supernatants were titrated in doubling dilutions on HEp-2 cell monolayers in 96well plates. $24 \mathrm{~h}$ later, cells were fixed with methanol and incubated with biotinylated anti-RSV antibody (Biogenesis, AbD Serotec, Oxford, UK) followed by peroxidase-conjugated Avidin (Sigma, Dorset, UK). DAB substrate (Sigma Fast Tablets) was added and plaques enumerated by light microscopy. Results are expressed as PFU per lung and the antiviral effect expressed as $\Delta \log _{10}$ in comparison to control group.

\section{Histopathology}

In some studies, unwashed lungs were formalin-fixed and embedded in paraffin, sectioned, and stained with haematoxylin-eosin (HE). Lungs were evaluated for inflammatory infiltrates and graded similarly to the classification described by PONNURAJ et al. [22]. The method was validated in our lab. Three sections from the upper, medium and lower lung were scored blindly in a random order according to the degree of inflammation in interstitium, alveoli, surrounding airways and vessels. A value of 0 (none), 1 (minimal), 2 (mild), 3 (moderate), or 4 (severe) was assigned to each site. The sum of these scores for each animal was used as a total lung inflammation score. Random slides were scored by a second observer and results were compared when sample codes were revealed.

\section{Bronchoalveolar lavage cell counting}

Bronchoalveolar lavage (BAL) was performed by infusing the lungs with $2 \%$ lidocaine in Earle's Balanced Salt Solution containing $2 \%$ bovine serum albumin. Total viable BAL cells were counted from samples diluted in Trypan blue $(0.4 \%)$, using light microscopy.

For differential counts, $100 \mu \mathrm{L}$ of BAL was spun onto slides at $100 \times g$ for $5 \mathrm{~min}$; slides were dried, fixed with methanol and stained with HE. 300 cells were counted from each sample and macrophages, polymorphs (paying attention to eosinophils) and lymphocytes were scored.

\section{TMC353121 bioanalysis}

The cryotubes for TMC353121 bioanalysis were decontaminated for possible live RSV virus by the addition of three parts of absolute ethanol for one part of sample. Serum and tissue samples were analysed individually for TMC353121 by means of a qualified research liquid chromatography-tandem mass spectrometry method. The limit of detection for TMC353121 was $1 \mathrm{ng} \cdot \mathrm{g}^{-1}$ for lung tissue and $0.8 \mathrm{ng} \cdot \mathrm{mL}^{-1}$ for serum.

\section{Luminex}

Cytokine levels in the BAL were quantified using multiplex immunoassay (MILLIPLEX MAP Kit; Millipore, Watford, UK) according to the manufacturer's instructions. BAL samples were assayed with appropriate standards and controls for each cytokine. Beads were added to duplicate samples and the plates were incubated overnight at $4^{\circ} \mathrm{C}$. Detection antibodies were added and plates incubated on a shaker followed by addition of streptavidin-phycoerythrin to each well. After washing, sheath fluid (PBS 1X) was added and the plates were run on Luminex $100^{\mathrm{TM}}$ (Luminex Corp., Austin, TX, USA). The median fluorescent intensity was analysed using StarStation and the concentrations for each cytokine calculated. Detection limit for each cytokine was $3.2 \mathrm{pg} \cdot \mathrm{mL}^{-1}$.

\section{Data analysis}

Viral loads were expressed as median log viral load. Changes in viral load $(\Delta \log )$ were calculated as difference between median log viral logs between untreated and treated groups.

GraphPad Prism software (GraphPad Software Inc., La Jolla, CA, USA) was used for one way ANOVA or Kruskal-Wallis test to investigate differences between groups. Comparisons of treatments were conducted using Dunn's or Tukey's tests. A trend of a dose-response curve was evaluated using linear trend test. General linear mixed model was used for the analysis of pharmacokinetic data and for body weight change over time. Cytokine concentrations were analysed using one way ANOVA. Statistical tests used are indicated in figure legends.

\begin{tabular}{|c|c|c|c|c|}
\hline \multicolumn{2}{|c|}{ In vivo protocol } & \multicolumn{3}{|c|}{ TaqMan Lung } \\
\hline Study & Treatment & Log viral load & $\Delta \log ^{\#}$ & p-value \\
\hline \multicolumn{5}{|l|}{ Study 1} \\
\hline \multirow[t]{3}{*}{ TMC353121 } & Day -5 to 0 & $5.69 \pm 0.54$ & $0.94 \pm 0.49$ & $>0.05$ \\
\hline & Day 0 & $6.23 \pm 0.47$ & $0.4 \pm 0.42$ & $>0.05$ \\
\hline & Day 0 to +3 & $5.14 \pm 2.07$ & $1.49 \pm 1.88$ & $<0.05$ \\
\hline Vehicle & Day -5 to +3 & $6.63 \pm 0.51$ & 0 & NA \\
\hline \multicolumn{5}{|l|}{ Study 2} \\
\hline \multirow[t]{4}{*}{ TMC353121 } & Day 0 to +3 & $4.92 \pm 0.2$ & $0.76 \pm 0.2$ & $>0.05$ \\
\hline & Day +1 to +3 & $4.98 \pm 0.2$ & $0.7 \pm 0.2$ & $>0.05$ \\
\hline & Day +2 to +3 & $4.64 \pm 1.28$ & $1.03 \pm 1.28$ & $<0.05$ \\
\hline & Day +3 to +3 & $5.55 \pm 0.55$ & $0.12 \pm 0.54$ & $>0.05$ \\
\hline Vehicle & Day 0 to +3 & $5.67 \pm 0.5$ & 0 & NA \\
\hline
\end{tabular}

Data are presented as median log value $\pm S D$, unless otherwise stated. NA: not applicable. Respiratory syncytial virus titres were measured by Taqman PCR for the $L$ gene, 4 days after infection. TMC353121 was administered by intravenous bolus, at $10 \mathrm{mg} \cdot \mathrm{kg}^{-1}$ dose, on indicated days. ${ }^{\#}$ : the median log reduction in lung was calculated versus untreated control; ${ }^{\top}$ : p-values for differences between viral loads for untreated versus treated groups were calculated using Kruskal-Wallis with Dunn's post-test. 5-6 mice per group were tested. Bold indicates statistical significance. 


\begin{tabular}{|c|c|c|c|c|c|c|}
\hline \multicolumn{3}{|c|}{ In vivo protocol } & \multicolumn{2}{|c|}{ TaqMan } & \multicolumn{2}{|c|}{ Plaque assay } \\
\hline \multirow[t]{3}{*}{ Study 3} & $10 \mathrm{mg} \cdot \mathrm{kg}^{-1}$ & $4.65 \pm 0.55$ & $1.02 \pm 0.18$ & $<0.01$ & $0.82 \pm 0.12$ & $<0.001$ \\
\hline & $5 \mathrm{mg} \cdot \mathrm{kg}^{-1}$ & $4.98 \pm 1.28$ & $0.69 \pm 0.28$ & $<0.05$ & $0.69 \pm 0.09$ & $<0.001$ \\
\hline & $0 \mathrm{mg} \cdot \mathrm{kg}^{-1}$ & $5.67 \pm 0.5$ & 0 & NA & 0 & NA \\
\hline \multirow[t]{5}{*}{ Study 4} & $10 \mathrm{mg} \cdot \mathrm{kg}^{-1}$ & $4.97 \pm 0.21$ & $0.58 \pm 0.69$ & $>0.05$ & $0.73 \pm 0.05$ & $<0.001$ \\
\hline & $2.5 \mathrm{mg} \cdot \mathrm{kg}^{-1}$ & $5.00 \pm 0.19$ & $0.55 \pm 0.29$ & $>0.05$ & $0.59 \pm 0.13$ & $<0.001$ \\
\hline & $1 \mathrm{mg} \cdot \mathrm{kg}^{-1}$ & $5.25 \pm 0.29$ & $0.31 \pm 0.19$ & $>0.05$ & $0.56 \pm 0.09$ & $<0.001$ \\
\hline & $0.25 \mathrm{mg} \cdot \mathrm{kg}^{-1}$ & $4.99 \pm 0.69$ & $0.56 \pm 0.21$ & $>0.05$ & $0.53 \pm 0.04$ & $<0.001$ \\
\hline & $0 \mathrm{mg} \cdot \mathrm{kg}^{-1}$ & $5.55 \pm 0.17$ & 0 & NA & 0 & NA \\
\hline
\end{tabular}

Data are presented as median log value \pm SD, unless otherwise stated. NA: not applicable. Respiratory syncytial virus (RSV) titres were measured by Taqman PCR and plaque assay 4 days after infection. TMC353121 was administered once by intravenous bolus, 60 min prior to RSV challenge. ${ }^{\#}$ : the median viral log reduction in lung was calculated versus untreated control; ': p-values were calculated using one way ANOVA with Tukeys' multiple comparison tests. 4-6 mice per group were tested. Bold indicates statistical significance.

\section{Experimental design}

The antiviral activity of TMC353121 was analysed in five studies. The compound was administered either before, or after RSV infection, and immunological parameters tested as outcome of such interventions. Drug was delivered via i.v. slow bolus once daily, as a single dose or as multiple doses for successive days. In some studies, different doses of the drug were administered as one single dose, before RSV challenge. Details of the experimental design are presented in figure 1a.

\section{RESULTS}

\section{Pharmacokinetics of TMC353121 in BALB/c mouse}

TMC353121 was administered once, i.v. at $2.5 \mathrm{mg} \cdot \mathrm{kg}^{-1}$ or at $0.25 \mathrm{mg} \cdot \mathrm{kg}^{-1}$. Drug levels were determined in lung tissue, serum (online supplementary figure 1), and BAL fluid (data not shown) at different time points. TMC353121 followed multicompartment pharmacokinetics, with a fast decay in serum within the first hour after i.v. injection, followed by a slower decay. The drug was eliminated quickly from the blood resulting in very low blood levels after $24 \mathrm{~h}$. Lung concentrations were much higher than serum concentrations and in BAL fluid the drug was just above the limit of detection at $8 \mathrm{~h}$ after injection (data not shown). Very low drug levels could still be detected in the lung 5 days after treatment (data not shown).

\section{TMC353121 prevents virus-induced weight loss}

Intranasal inoculation with $2 \times 10^{6}$ PFU of RSV on day 0 resulted in substantial weight loss on day 6 and 7 post infection (fig. 1b). Daily administration of TMC353121 before infection (day -5 to 0 ) or starting from the day of infection (day 0 to +3 ) was able to significantly abolish the weight loss effect of RSV infection (fig. 1b). Importantly, a single dose of TMC353121 was able to completely prevent weight loss. On day 7, a significantly lower weight was observed in the control than in treated groups, whereas no significant differences were shown between treated groups.

\section{TMC353121 reduces viral load in therapeutic and prophylactic administration}

Administration of TMC353121 resulted in reduced viral load compared to untreated controls. The median reduction in viral load was $0.94 \pm 0.49 \log$ (day -5 to 0 ) and $1.49 \pm 1.88 \log$ (day 0 to +3 ) for repetitive administration, compared with $0.4 \pm 0.42 \log$ reduction for a single administration (table 1).

The second study analysed the efficacy of TMC353121 in different therapeutic regimens. The compound was administered daily with delays in relation to RSV challenge (study 2; table 1, fig. 1a). In this study, lower level of infection was observed (control group: $5.67 \pm 0.5 \log$ versus $6.63 \pm 0.51 \mathrm{log}$ ), in comparison to study 1 ; however, $0.7-1 \log$ reduction in viral load was observed when drug was administered with increasing delay, up to day 2 after RSV challenge.

\section{TMC353121 has significant antiviral activity in a wide dose range in $B A L B / c$ mice}

The antiviral efficacy of TMC353121 was explored in a wide dose range in prophylactic regimens with the drug administered as a single dose; 60 min prior to RSV challenge (studies 3 and 4 ; table 2).

In both studies, similar titres of RSV viral load were recovered in untreated controls $(5.67 \pm 0.5 \log$ versus $5.55 \pm 0.17 \mathrm{log})$. Based on real-time RT-PCR, TMC 353121 administration within the dose range $0.25-10 \mathrm{mg} \cdot \mathrm{kg}^{-1}$ resulted in $0.5-1 \Delta \mathrm{log}$ viral load reduction compared to untreated groups. These differences were significant for all doses in study 3, but not in study 4 (table 2). However, by the plaque assay, all analysed doses of TMC353121 in both studies showed statistically significant reductions in PFU per lung.

\section{TMC353121 reduces lung inflammation}

TMC353121 reduced BAL cell influx in all tested doses. The reduction in cellular infiltration was attributed mainly to macrophages and lymphocytes (fig. 2a). For the dose range 1$10 \mathrm{mg} \cdot \mathrm{kg}^{-1}$, the level of total cell accumulation in BAL was 


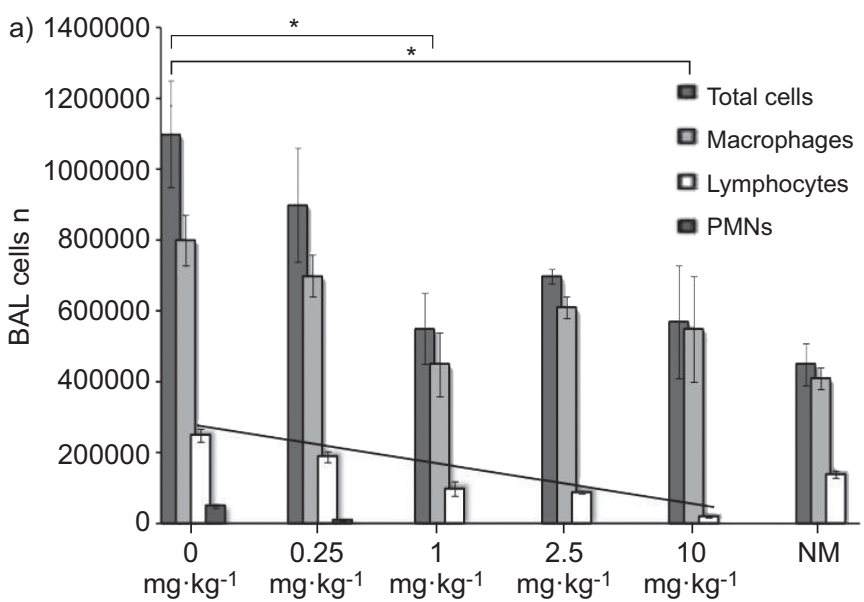

b)

$\mathrm{B}_{1}$

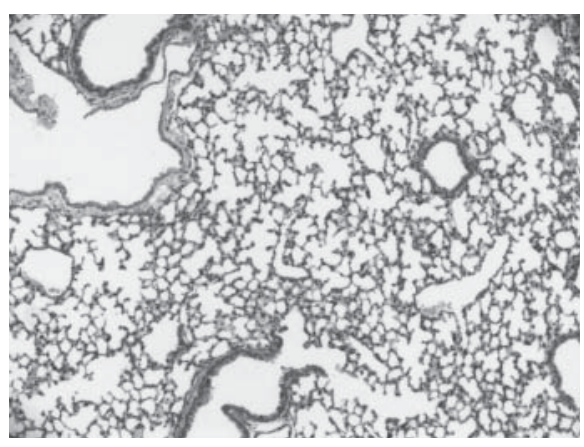

Group $\mathrm{B}_{1}$

2

Individual

(Interstitial=1, perivascular $=0$, alveolar $=1$, peribronchiolar $=0$ )

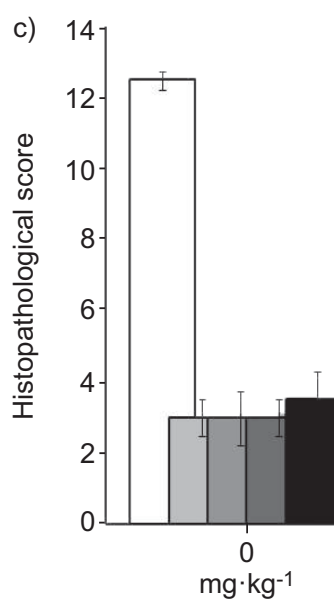

口 Total score

口 Interstitial score

口 Alveolar score

- Peribronchiolar score

- Perivascular score

$\mathrm{B}_{2}$

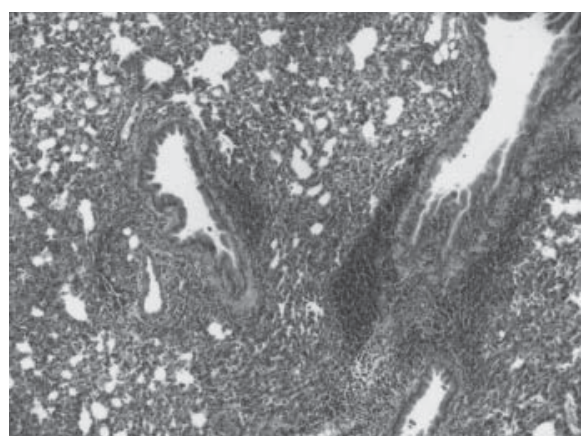

$\mathrm{B}_{2}$

14

(Interstitial $=4$, perivascular $=4$, alveolar $=3$, peribronchiolar $=3$ )
4

(Interstitial=2, perivascular $=0$, alveolar $=2$, peribronchiolar $=0$ )

FIGURE 2. a) Bronchoalveolar lavage (BAL) cell influx is inhibited in TMC353121-treated, respiratory syncytial virus (RSV)-infected animals. Mice were culled on day 4 after infection and viable BAL cells were counted using Trypan blue exclusion and differential counts were performed after haematoxylin-eosin (HE) staining of cytospins. Mice (five per group) received one intravenous injection $1 \mathrm{~h}$ prior to RSV infection containing TMC535121 at indicated dose, or vehicle control. NM: noninfected mouse. Data are presented as mean \pm SE. *: significant difference of $p<0.05$ between total cell numbers. Multiple comparison was done with one way ANOVA with Dunnett test. Linear trend for lymphocytes accumulation versus TMC353121 doses was assessed with one way ANOVA with post-test for linear trend. b) Significantly reduced lung cellular infiltrates in TMC353121-treated, RSV-infected animals. Representative slides for HE staining of lung sections. $\mathrm{B}_{1}$ : noninfected lung; $\mathrm{B}_{2}$ : RSV-infected lung; $\mathrm{B}_{3}$ : TMC353121treated $\left(10 \mathrm{mg} \cdot \mathrm{kg}^{-1}\right)$ and RSV-infected lung. Lungs were analysed 5 days after infection. Figures underneath indicate how the particular views were graded. Details of the scoring system are described in the Materials and methods section. c) Lung histopathological score in a representative experiment. Lung sections were stained with HE to assess cell infiltrate and their localisation. Lungs were graded according to a scheme similar to that described by PonNuRAs et al. [22]. In this experiment, each group consisted of two mice. Three lung sections (upper, medium and lower horizontal segments) were evaluated per lung. NM: noninfected, nontreated mice. Median of total histopathological score and tissue-specific scores are shown. Multiple comparisons between groups were done using Kruskal-Wallis with Dunn's test. **: significant difference of $p<0.005$. $p$-values for $10-\mathrm{mg} \mathrm{kg}^{-1}$ groups versus the $0-\mathrm{mg} \cdot \mathrm{kg}^{-1}$ group (saline) are shown. Such an assessment was performed in four more studies using $2-5$ mice per group. PMN: polymorphonuclear leukocytes.

similar to that in noninfected mice, whereas the total amount of BAL cells was roughly doubled in RSV-infected untreated mice compared with RSV-infected treated mice (fig. 2a).

Lung sections were stained with HE to assess the localisation and extent of cell infiltrates. A total histopathological score of 12 for untreated mice indicated a clinically significant RSV infection leading to accumulation of inflammatory cells in the bronchiolar and alveolar space (fig. 2c). The total score and scores in various compartments (interstitial, alveolar, peribronchiolar and perivascular) of treated mice were significantly reduced compared with the RSV-infected, untreated control group and showed values similar to the noninfected control group (fig. 2c). Examples of tissue sections stained for histopathology evaluation are presented in figure $2 \mathrm{~b}$. There was no visual difference between the noninfected control group and the infected, treated group. The improved lung histopathology in the presence of TMC353121 treatment was confirmed in another study, for doses lower than $10 \mathrm{mg} \cdot \mathrm{kg}^{-1}$ dose (data not shown).

TMC353121 significantly reduced levels of tested chemokines and cytokines in the BAL (fig. 3). In TMC353121-treated and 

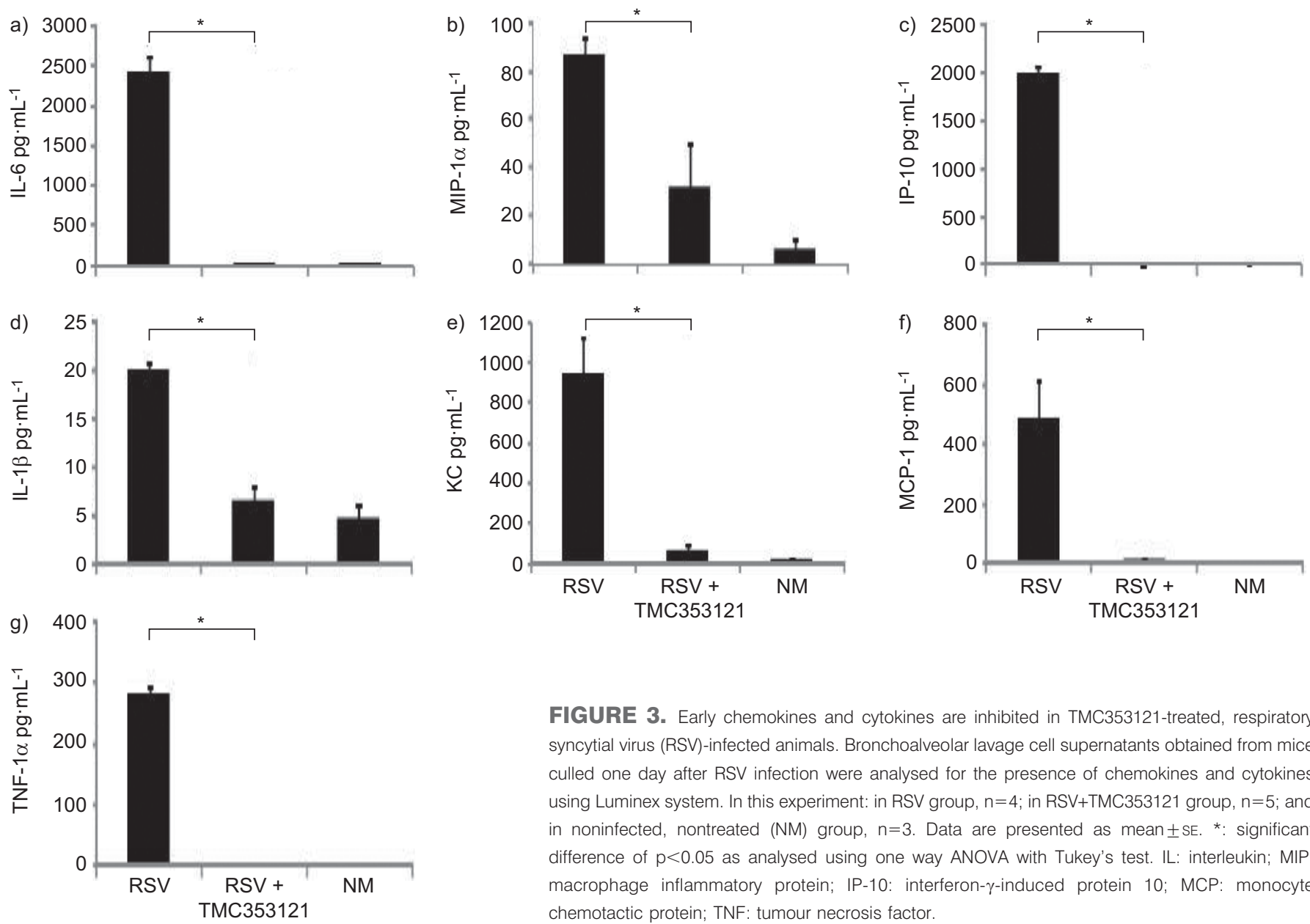

FIGURE 3. Early chemokines and cytokines are inhibited in TMC353121-treated, respiratory syncytial virus (RSV)-infected animals. Bronchoalveolar lavage cell supernatants obtained from mice culled one day after RSV infection were analysed for the presence of chemokines and cytokines using Luminex system. In this experiment: in RSV group, $n=4$; in RSV+TMC353121 group, $n=5$; and in noninfected, nontreated (NM) group, $n=3$. Data are presented as mean \pm SE. *: significant difference of $p<0.05$ as analysed using one way ANOVA with Tukey's test. IL: interleukin; MIP: macrophage inflammatory protein; IP-10: interferon- $\gamma$-induced protein 10; MCP: monocyte chemotactic protein; TNF: tumour necrosis factor.

RSV-infected animals, very significant reduction in inflammatory cytokines (such as tumour necrosis factor (TNF)- $\alpha$, interleukin (IL)-6 and IL-1 $\beta$ ) and chemokines (interferon- $\gamma$ induced protein 10 (IP-10), KC, macrophage inflammatory protein (MIP)- $1 \alpha$ and monocyte chemotactic protein (MCP)) in BAL was observed $24 \mathrm{~h}$ later. The same set of cytokines/ chemokines was investigated 4 days later, but there were no more significant differences, and some cytokines were below the limit of detection (online supplementary figure 2). IP-10 and $\mathrm{KC}$ were also present in serum $24 \mathrm{~h}$ post RSV infection, and were significantly reduced in animals receiving TMC353121 (data not shown).

\section{DISCUSSION}

Our results demonstrate potent antiviral activity of the fusion inhibitor TMC353121 in the murine model of RSV infection. The drug was well tolerated, and prevented weight loss characteristic of RSV infection in mice [23]. In these studies, optimal recovery of body weight was seen even after single drug administration (fig. 1b).

Pharmacokinetic studies showed that TMC353121 was present in the serum at concentrations above the target inhibitory concentration $\left(7 \mathrm{ng} \cdot \mathrm{mL}^{-1}\right)$ for the first $24 \mathrm{~h}$ for the $2.5 \mathrm{mg}$ dose and less for the $0.25 \mathrm{mg} \cdot \mathrm{kg}^{-1}$ dose (online supplementary figure 1). The targeted plasma concentration was calculated based on the half maximal effective concentration value of
$0.07 \mathrm{pg} \cdot \mathrm{mL}^{-1}$ obtained in the in vitro assay [24], assuming $100 \%$ protein binding. The compound is quickly eliminated from the body; however, its high potency seems to balance rapid elimination.

The BALB/c mouse model is semi-permissive for RSV, with limited viral replication in lung epithelial cells. In BALB/c mice, RSV first infects epithelial cells in nasal cavities [25] and spreads to the lung, where it peaks around day 4 after infection. Optimally, RSV fusion inhibitors should be present at the time of infection to block virus entry to the cell. The results presented here for TMC353121 in therapeutic regimens (study 2; table 1) demonstrate that the drug is able to reduce viral replication when administered 2 days after RSV challenge, confirming that sustained viral replication does occur in this murine model and can be inhibited even by delayed drug administration. In comparison, other $\mathrm{F}$ protein fusion inhibitors, such as BMS-433771 and RFI-641, were not effective when used therapeutically in the murine model $[13,26]$, although RFI-641 showed efficacy in the African Green Monkey when administered in this manner [27].

TMC353121 reduced viral load in a broad dose range, 0.25 $10 \mathrm{mg} \cdot \mathrm{kg}^{-1}$, when measured by Taqman and plaque assay. Both methods quantify RSV in different ways; TaqMan RTPCR measures the number of RSV-L-gene copies (present in both infectious virus and in defective particles), while the 
plaque assay quantifies fully functional infectious virions. This RT-PCR method does not distinguish between virus used for the challenge and newly produced viral particles therefore additional information from the functional assay is pivotal in accurate data interpretation.

In our study, infected and treated mice showed reduced cell influx into BAL fluid compared to nontreated controls, and a dose-dependent reduction in lymphocyte numbers $(p<0.05$ for linear trend; fig. 2a). Lung histopathology was analysed at the time of the highest lung inflammation in murine model [28] characterised by a pneumonia $[25,29]$ with macrophages and lymphocytes infiltrating perivascular and peribronchiolar tissues [25]. TMC353121-treated mice demonstrated histopathology sections similar to those of normal mice (fig. $2 \mathrm{~b}$ and $\mathrm{c}$.

The protective effect of TMC353121 on lung histopathology correlates with the reduction of viral replication. Although one would consider this type of correlation obvious, it is not always the case. Notably, the anti-F protein monoclonal antibody palivizumab significantly reduces viral load but does not improve lung histopathology and lung inflammation in the cotton rat RSV model [30]. In the same study, Numax showed better antiviral activity and improvement in lung histopathology than palivizumab. Discrepancy between our results and those of others may be explained by different mechanisms of action of the compounds. Complexes formed by antibodies with viruses must be cleared by antigen-presenting cells and this process initiates immune pathways leading to release of chemokines attracting other cells (mainly lymphocytes) to the lung. This is reflected in histopathology as cell infiltrates are visible, attracted by antigen/antibody complexes. In contrast, TMC353121 blocks fusion of virus with a target cell and this process is not associated with release of chemokines, therefore other cells are not attracted to the lungs.

As we show here, RSV infection leads, within hours, to release and production of chemokines and inflammatory cytokines (RSV-infected and vehicle-treated in figure 3) resulting in increased numbers of macrophages, lymphocytes and neutrophils. In our model, reduction in IP-10, IL-1 $\beta$, KC, MIP-1 $\alpha$, MCP-1, IL- 6 and TNF- $\alpha$ levels in mice treated with TMC353121 (fig. 3 ) coincides with reduced numbers of BAL cells, mainly in macrophage and lymphocyte subsets (fig. 2a), suggesting pivotal role of chemokines in BAL cell recruitment at early stage of lung inflammation. These mediators return to levels not different from those in normal animals within 4 days in both nontreated and drug-treated groups (online supplementary figure 2).

The neonatal immune system is inherently biased towards Thelper type 2 responses and RSV infection early in life may further enhance these responses. The ideal intervention for RSV infection would be preventive, but the options are currently limited. The significant antiviral activity, particularly when used in therapeutic regimen and the protective effect on lung inflammation make TMC353121 a promising candidate for treatment of bronchiolitis and respiratory complications caused by RSV infection. Further research is required in order to better understand the protective mechanisms and to validate this molecule for RSV treatment.

\section{STATEMENT OF INTEREST}

Statements of interest for G. Ispas, T. Van de Casteele, B. Van Kerckhove, D. Roymans, M. De Meulder, P. Van Remoortere, J.F. Bonfanti, F. Van Velsen, A. Koul, M. Vanstockem, K. Andries, P. Openshaw and R. Verloes can be found at www.erj.ersjournals.com/ site/misc/statements.xhtml

\section{ACKNOWLEDGEMENTS}

The work was sponsored by the Flemish Community IWT 070005 project. B. Wang and P. Openshaw were supported by the Wellcome Trust grant 071381/Z/03/Z. The authors thank F. Culley (Imperial College London, London, UK) for critical reading of the manuscript.

\section{REFERENCES}

1 Smyth RL, Openshaw PJ. Bronchiolitis. Lancet 2006; 368: 312-322.

2 Hall CB, Long CE, Schnabel KC. Respiratory syncytial virus infections in previously healthy working adults. Clin Infect Dis 2001; 33: 792-796.

3 Leader S, Kohlhase K. Respiratory syncytial virus-coded pediatric hospitalizations, 1997 to 1999. Pediatr Infect Dis J 2002; 21: 629-632.

4 Sigurs N, Bjarnason R, Sigurbergsson F, et al. Respiratory syncytial virus bronchiolitis in infancy is an important risk factor for asthma and allergy at age 7. Am J Respir Crit Care Med 2000; 161: 1501-1507.

5 Freymuth F, Vabret A, Gouarin S, et al. [Epidemiology and diagnosis of respiratory syncitial virus in adults]. Rev Mal Respir 2004; 21: 35-42.

6 Falsey AR, Hennessey PA, Formica MA, et al. Respiratory syncytial virus infection in elderly and high-risk adults. $N$ Engl $J$ Med 2005; 352: 1749-1759.

7 Krilov LR. Safety issues related to the administration of ribavirin. Pediatr Infect Dis J 2002; 21: 479-481.

8 Hashmi NA, Cosgrove JF, MacMahon P. Prophylaxis in RSV infection (Palivizumab) - is it worthwhile? Ir Med J 2000; 93: 284.

9 Barton LL, Grant KL, Lemen RJ. Respiratory syncytial virus immune globulin: decisions and costs. Pediatr Pulmonol 2001; 32: 20-28.

10 Meissner HC, Long SS. Revised indications for the use of palivizumab and respiratory syncytial virus immune globulin intravenous for the prevention of respiratory syncytial virus infections. Pediatrics 2003; 112: 1447-1452.

11 Kim HW, Canchola JG, Brandt CD, et al. Respiratory syncytial virus disease in infants despite prior administration of antigenic inactivated vaccine. Am J Epidemiol 1969; 89: 422-434.

12 Douglas JL, Panis ML, Ho E, et al. Small molecules VP-14637 and JNJ-2408068 inhibit respiratory syncytial virus fusion by similar mechanisms. Antimicrob Agents Chemother 2005; 49: 2460-2466.

13 Cianci C, Genovesi EV, Lamb L, et al. Oral efficacy of a respiratory syncytial virus inhibitor in rodent models of infection. Antimicrob Agents Chemother 2004; 48: 2448-2454.

14 Cianci C, Langley DR, Dischino DD, et al. Targeting a binding pocket within the trimer-of-hairpins: small-molecule inhibition of viral fusion. Proc Natl Acad Sci USA 2004; 101: 15046-15051.

15 Razinkov V, Gazumyan A, Nikitenko A, et al. RFI-641 inhibits entry of respiratory syncytial virus via interactions with fusion protein. Chem Biol 2001; 8: 645-659.

16 Andries K, Moeremans M, Gevers T, et al. Substituted benzimidazoles with nanomolar activity against respiratory syncytial virus. Antiviral Res 2003; 60: 209-219.

17 Bonfanti JF, Doublet F, Fortin J, et al. Selection of a respiratory syncytial virus fusion inhibitor clinical candidate, part 1: improving the pharmacokinetic profile using the structure-property relationship. J Med Chem 2007; 50: 4572-4584. 
18 Olszewska W, Openshaw P. Emerging drugs for respiratory syncytial virus infection. Expert Opin Emerg Drugs 2009; 14: 207-217.

19 Bonfanti JF, Meyer C, Doublet F, et al. Selection of a respiratory syncytial virus fusion inhibitor clinical candidate. 2. Discovery of a morpholinopropylaminobenzimidazole derivative (TMC353121). J Med Chem 2008; 51: 875-896.

20 Roymans D, De Bondt HL, Arnoult E, et al. Binding of a potent small-molecule inhibitor of six-helix bundle formation requires interactions with both heptad-repeats of the RSV fusion protein. Proc Natl Acad Sci USA 2010; 107: 308-313.

21 Olszewska W, Broeckaert F, Ispas G, et al. Anti-viral and antiinflammatory activities of TMC353121, a potent antiviral fusion inhibitor, in a mouse model of RSV infection. RSV Symposium, Marco Island, Florida. 2007. Available from: http://faculty. virginia.edu/RSV2007/Abstracts_Final_Program.pdf

22 Ponnuraj EM, Hayward AR, Raj A, et al. Increased replication of respiratory syncytial virus (RSV) in pulmonary infiltrates is associated with enhanced histopathological disease in bonnet monkeys (Macaca radiata) pre-immunized with a formalin-inactivated RSV vaccine. J Gen Virol 2001; 82: 2663-2674.

23 Bolger G, Lapeyre N, Dansereau N, et al. Primary infection of mice with high titer inoculum respiratory syncytial virus: characterization and response to antiviral therapy. Can J Physiol Pharmacol 2005; 83: 198-213.
24 Bonfanti JF, Roymans D. Prospects for the development of fusion inhibitors to treat human respiratory syncytial virus infection. Curr Opin Drug Discov Devel 2009; 12: 479-487.

25 Taylor G, Stott EJ, Hughes M, et al. Respiratory syncytial virus infection in mice. Infect Immun 1984; 43: 649-655.

26 Wyde PR, Moore-Poveda DK, O'Hara B, et al. CL387626 exhibits marked and unusual antiviral activity against respiratory syncytial virus in tissue culture and in cotton rats. Antiviral Res 1998; 38: $31-42$.

27 Huntley CC, Weiss WJ, Gazumyan A, et al. RFI-641, a potent respiratory syncytial virus inhibitor. Antimicrob Agents Chemother 2002; 46: 841-847.

28 Chavez-Bueno S, Mejias A, Gomez AM, et al. Respiratory syncytial virus-induced acute and chronic airway disease is independent of genetic background: an experimental murine model. Virol J 2005; 2: 46 .

29 Anderson JJ, Norden J, Saunders D, et al. Analysis of the local and systemic immune responses induced in BALB/c mice by experimental respiratory syncytial virus infection. J Gen Virol 1990; 71: 1561-1570.

30 Mejias A, Chavez-Bueno S, Rios AM, et al. Comparative effects of two neutralizing anti-respiratory syncytial virus (RSV) monoclonal antibodies in the RSV murine model: time versus potency. Antimicrob Agents Chemother 2005; 49: 4700-4707. 